\title{
Premedication with pioglitazone prevents doxorubicin-induced left ventricular dysfunction in mice
}

\author{
Takaaki Furihata $^{1 * \dagger}$, Satoshi Maekawa ${ }^{1 \dagger}$, Shingo Takada ${ }^{1,2}$, Naoya Kakutani ${ }^{1,3}$, Hideo Nambu', Ryosuke Shirakawa', \\ Takashi Yokota ${ }^{1}$ and Shintaro Kinugawa ${ }^{1}$
}

\begin{abstract}
Background: Doxorubicin (DOX) is widely used as an effective chemotherapeutic agent for cancers; however, DOX induces cardiac toxicity, called DOX-induced cardiomyopathy. Although DOX-induced cardiomyopathy is known to be associated with a high cumulative dose of DOX, the mechanisms of its long-term effects have not been completely elucidated. Pioglitazone (Pio) is presently contraindicated in patients with symptomatic heart failure owing to the side effects. The concept of drug repositioning led us to hypothesize the potential effects of Pio as a premedication before DOX treatment, and to analyze this hypothesis in mice.

Methods: First, for the hyperacute (day 1) and acute (day 7) DOX-induced dysfunction models, mice were fed a standard diet with or without 0.02\% (wt/wt) Pio for 5 days before DOX treatment (15 mg/kg body weight [BW] via intraperitoneal [i.p.] administration). The following 3 treatment groups were analyzed: standard diet + vehicle (Vehicle), standard diet + DOX (DOX), and Pio + DOX. Next, for the chronic model (day 35), the mice were administrated DOX once a week for 5 weeks (5 mg/kg BW/week, i.p.).

Results: In the acute phase after DOX treatment, the percent fractional shortening of the left ventricle (LV) was significantly decreased in DOX mice. This cardiac malfunction was improved in Pio + DOX mice. In the chronic phase, we observed that LV function was preserved in Pio + DOX mice.

Conclusions: Our findings may provide a new pathophysiological explanation by which Pio plays a role in the treatment of DOX-induced cardiomyopathy, but the molecular links between Pio and DOX-induced LV dysfunction remain largely elusive.
\end{abstract}

Keywords: Anticancer agent, LV dysfunction, Cardiac toxicity, Thiazolidinediones

\section{Background}

Cardiotoxicity, which is generally defined as toxicity that affects the heart, has become a major medical issue, because adverse heart reactions to chemotherapy lead to increased morbidity and mortality [1]. Although the

\footnotetext{
* Correspondence: takaaki.furihata@gmail.com

${ }^{\dagger}$ Takaaki Furihata and Satoshi Maekawa contributed equally to this work. 'Department of Cardiovascular Medicine, Faculty of Medicine and Graduate School of Medicine, Hokkaido University, Kita-15, Nishi-7, Kita-ku, Sapporo 060-8638, Japan

Full list of author information is available at the end of the article
}

anthracycline antibiotic doxorubicin (DOX) is widely used as a very effective chemotherapeutic drug for hematological as well as solid cancers, DOX unfortunately induces many kinds of cardiac toxic effects, such as transient arrhythmias, nonspecific electrocardiographic abnormalities, and cardiomyopathy [2, 3]. Some clinical studies have suggested that late-onset DOXinduced cardiomyopathy is strongly associated with a high cumulative dose of DOX [4]. For example, doxorubicin leads to a $5 \%$ incidence of congestive HF if a

(C) The Author(s). 2021 Open Access This article is licensed under a Creative Commons Attribution 4.0 International License, which permits use, sharing, adaptation, distribution and reproduction in any medium or format, as long as you give appropriate credit to the original author(s) and the source, provide a link to the Creative Commons licence, and indicate if changes were made. The images or other third party material in this article are included in the article's Creative Commons licence, unless indicated otherwise in a credit line to the material. If material is not included in the article's Creative Commons licence and your intended use is not permitted by statutory regulation or exceeds the permitted use, you will need to obtain permission directly from the copyright holder. To view a copy of this licence, visit http://creativecommons.org/licenses/by/4.0/ The Creative Commons Public Domain Dedication waiver (http://creativecommons.org/publicdomain/zero/1.0/) applies to the data made available in this article, unless otherwise stated in a credit line to the data. 
cumulative lifetime dose of $400 \mathrm{mg} / \mathrm{m}^{2}$ is taken, $26 \%$ at $550 \mathrm{mg} / \mathrm{m}^{2}$, and $48 \%$ at $700 \mathrm{mg} / \mathrm{m}^{2}$ [5]. The underlying mechanisms of both acute-onset and late-onset cardiotoxicity have been thought to include several factors, such as oxidative stress, iron overload, mitochondrial dysfunction, and DNA damage [6]. Nonetheless, a standard therapy for the treatment or prevention of DOXinduced cardiomyopathy has not been established to date, which has created an obstacle in cancer treatments.

Thiazolidinediones (TZDs), including pioglitazone (Pio), have been shown to improve the disease state of type II diabetic and metabolic syndrome patients, mainly through the improvement of insulin resistance [7]. More importantly, TZDs were shown to improve left ventricular (LV) function in mice with heart failure (HF) after myocardial infarction [8], and to reduce the risk of major adverse cardiovascular events in people with insulin resistance [9]. Furthermore, there was a study that showed Pio played a protective role in doxorubicin-induced nephropathy in rat to a similar extent as an angiotensin converting enzyme inhibitor, improving profibrotic and inflammatory mechanisms [10]. However, an increased risk of HF owing to fluid retention upon Pio administration was strongly feared [11], such that presently, Pio is contraindicated for patients with symptomatic HF.

In recent years, there has been increasing interest in drug repositioning, which is a concept defined as the process of finding new uses for existing drugs, particularly in the field of cancer therapeutics [12]. Moreover, premedication has been used in other settings to reduce the risk of adverse events [13, 14]. We therefore hypothesized that Pio might reduce the adverse events of DOX, and may improve LV dysfunction caused by DOX treatment if used as a premedication, which is taking Pio before DOX treatment, rather than taking it at the same time or after developing HF. Therefore, to determine whether premedication with Pio prevents DOX-induced LV dysfunction, we analyzed cardiac function in a mouse model of DOX-induced LV dysfunction, with or without Pio premedication.

\section{Materials and methods \\ Ethics statement}

The study was conducted in accordance with the ARRIVE guidelines. The Hokkaido University Animal Research Committee approved all experimental procedures and methods of animal care (study approval no.: 130074). The Animal Care Guidelines for the Care and Use of Laboratory Animals of Hokkaido University Graduate School of Medicine and the Guide for the Care and Use of Laboratory Animals published by the US National Institutes of Health were applied to all experiments.

\section{Experimental animals and drug treatment protocol}

Eight-week-old male C57BL/6 J mice (23-25 g) were obtained from CLEA Japan, Inc. (Tokyo, Japan). They were maintained on specific diets in a pathogen-free environment in an animal room under controlled conditions on a 12-h light/dark cycle for 5 days. First, the mice were divided into 3 groups. Two of these groups were fed a standard diet (AIN93G, Oriental Yeast Co., Ltd., Tokyo, Japan); the third was fed the standard diet with $0.02 \%$ (wt/wt) Pio (pioglitazone hydrochloride; P1901, Tokyo Chemical Industry Co., Ltd., Tokyo, Japan) [15-17]. Next, the group of Pio-pretreated mice and one group of standard diet mice were treated with $15 \mathrm{mg} / \mathrm{kg}$ body weight (BW) of DOX (doxorubicin hydrochloride; D1515, Sigma-Aldrich, MO, USA) via intraperitoneal (i.p.) administration [18]. Mice in the other standard diet group were injected with phosphate-buffered saline as the vehicle (Vehicle). For the hyperacute model, 30 mice were divided into 3 groups of 10 mice each; i.e., Vehicle, DOX, and Pio + DOX. For the acute model, 76 mice were divided into 3 groups; i.e., Vehicle $(n=25)$, DOX $(n=26)$, and Pio + DOX $(n=26)$. Furthermore, for the chronic model, mice were treated with an injection of 5 $\mathrm{mg} / \mathrm{kg}$ BW of DOX via i.p. administration per week for 5 weeks [19], whereas the untreated mice were injected with phosphate-buffered saline as the vehicle. Thirty-five mice were divided into 3 groups; i.e., Vehicle $(n=7)$, DOX $(n=14)$, and Pio + DOX $(n=14)[18,20-22]$. One day and seven days after DOX treatment, or 5 weeks after the beginning of weekly injections, the hearts were excised after mice were euthanized under deep anesthesia with $0.3 \mathrm{mg} / \mathrm{kg}$ BW of medetomidine (Dorbene ${ }^{\bullet}$ Kyoritsuseiyaku Co., Ltd., Tokyo, Japan), $4.0 \mathrm{mg} /$ $\mathrm{kg} \mathrm{BW}$ of midazolam (Dormicum ${ }^{\circ}$, Astellas Pharma Inc., Tokyo, Japan), and $5.0 \mathrm{mg} / \mathrm{kg}$ BW of butorphanol (Vetorphale ${ }^{\circ}$ Meiji Seika Kaisha, Ltd., Tokyo, Japan) (MMB mixture) [23].

\section{Survival analysis}

Survival was analyzed in all groups of acute DOX model mice, i.e., Vehicle $(n=15)$, DOX $(n=15)$, and Pio + DOX $(n=15)$. During the 7 days after DOX injection, the cages were inspected daily for dead animals.

\section{Echocardiographic measurements}

Echocardiographic measurements were performed both 1 day and 7 days after drug treatments, under light anesthesia with the MMB mixture. Two-dimensional parasternal short-axis views were obtained at the levels of the papillary muscles. On-axis, two-dimensional targeted M-mode tracings, for at least 20 cardiac cycles, were electronically recorded (Aplio 300, TOSHIBA, Tokyo, Japan; EUB-8000, HITACHI, Tokyo, Japan). The following indexes were analyzed using the software in 
the echo instrument; LV end-diastolic diameter (LVED D), LV end-systolic diameter (LVESD), percent fractional shortening (\%FS), heart rates (HR), and LV wall thickness [23-28].

\section{Histological analyses}

Hearts were excised, fixed in $4 \%$ paraformaldehyde, embedded in paraffin, cut into three transverse sections (apex, middle ring, and base), and stained with HE for histological analyses. Morphological analysis of the cross-sectional area per cell was performed in at least 20 cells from each mouse, chosen appropriate cross-section and in the vertically aligned muscle layers adjacent to them, not tangentially $[29,30]$. For evaluation of the degree of fibrosis, hearts were stained with MT. After collagen fiber identification and quantification, collagen fiber areas were measured with ImageJ software $(\mathrm{NIH}$, MD, USA) [31]. Pictures were acquired using a microscope (BZ-X710, Keyence, Osaka, Japan) [23, 32].

\section{Quantitative reverse transcription polymerase chain reaction $(\mathrm{PCR})$}

Total RNA was extracted from heart tissues with QuickGene-810 (FujiFilm, Tokyo, Japan) according to the manufacturer's instructions. Total RNA concentration and purity were analyzed by measuring the optical density $(230,260$, and $280 \mathrm{~nm}$ ) with a Nanodrop 1000 spectrophotometer (Thermo Fisher Scientific, MA, USA). cDNA was synthesized with a high capacity cDNA reverse transcription kit (Applied Biosystems, CA, USA). Reverse transcription was performed for $10 \mathrm{~min}$ at $25^{\circ} \mathrm{C}, 120 \mathrm{~min}$ at $37^{\circ} \mathrm{C}, 5 \mathrm{~s}$ at $85^{\circ} \mathrm{C}$, and then the solution was cooled at $4{ }^{\circ} \mathrm{C}$. TaqMan quantitative real-time PCR was performed with the 7300 real-time PCR system (Applied Biosystems) to amplify interleukin-1beta (Il1b) (Mm00434227_g1) and tumor necrosis factor-alpha (Tnfa) (Mm01161290_g1) cDNA in the heart. After 2 min at $50{ }^{\circ} \mathrm{C}$ and $10 \mathrm{~min}$ at $95^{\circ} \mathrm{C}, \mathrm{PCR}$ amplification was performed for 40 cycles of $15 \mathrm{~s}$ at $95^{\circ} \mathrm{C}$ and $1 \mathrm{~min}$ at $60^{\circ} \mathrm{C}$. Glyceraldehyde-3-phosphate dehydrogenase (GAPDH) was used as an internal control. Data were analyzed using the comparative $2^{-\Delta \Delta C T}$ method $[25,26$, 33-35].

\section{Preparation of isolated mitochondria}

Heart tissues were quickly harvested after the mice were sacrificed, and mitochondria were isolated as previously described, and their protein concentrations were measured as described $[25,36]$. Briefly, after incubation for $2 \mathrm{~min}$ in mitochondrial isolation buffer $(100 \mathrm{mmol} / \mathrm{L} \mathrm{su}-$ crose, $100 \mathrm{mmol} / \mathrm{L} \mathrm{KCL}, 1 \mathrm{mmol} / \mathrm{L} \mathrm{KH}_{2} \mathrm{PO}_{4}, 0.1 \mathrm{mmol} / \mathrm{L}$ ethyleneglycol bis (2-aminoethyl ether)- $\mathrm{N}, \mathrm{N}, \mathrm{N}^{\prime}, \mathrm{N}^{\prime}$ tetraacetic acid (EGTA), $0.2 \%$ bovine serum albumin, and 50 $\mathrm{mmol} / \mathrm{L} \quad$ Tris- $\mathrm{HCl} ; \quad \mathrm{pH} 7.4) \quad$ containing $0.1 \mathrm{mg} / \mathrm{mL}$ proteinase (P8038, Sigma-Aldrich, MO, USA), minced hearts were homogenized with a motor-driven Teflon pestle in a glass chamber. Homogenates were centrifuged at $700 \mathrm{~g}$ for $10 \mathrm{~min}$, and then the supernatants were centrifuged at $10,000 \mathrm{~g}$ for $10 \mathrm{~min}$. Pellets were suspended in suspension buffer $(225 \mathrm{mmol} / \mathrm{L}$ mannitol, 75 $\mathrm{mmol} / \mathrm{L}$ sucrose, $10 \mathrm{mmol} / \mathrm{L}$ Tris, and $0.1 \mathrm{mmol} / \mathrm{L}$ ethylenediaminetetraacetic acid [EDTA], pH 7.4) [25].

\section{Mitochondrial oxidative phosphorylation (OXPHOS) capacity and reactive oxygen species (ROS) production with non-fatty-acids or fatty-acids in isolated heart mitochondria}

The mitochondrial respiratory capacity from non-fattyacids were measured in isolated heart mitochondria using a high-resolution respirometer (Oxygraph-2 k, Oroboros Instruments, Innsbruck, Austria), as described previously $[25,26,37]$. The following two protocols were used for the non-fatty-acid substrates and fatty-acid substrates. After the addition of isolated mitochondria of $\mathrm{LV}$ to the chamber in the respirometer filled with $2 \mathrm{~mL}$ of MiR05 (in $\mathrm{mmol} / \mathrm{L}$ : sucrose 110, K-lactobionate 60, EGTA 0.5, $\mathrm{MgCl}_{2} 3$, taurine 20, $\mathrm{KH}_{2} \mathrm{PO}_{4}$ 10, 4-(2-hydroxyethyl)-piperazineethanesulfonic acid [HEPES] 20, 1\% bovine serum albumin [BSA], $\mathrm{pH}$ 7.1), we added the substrates, and adenosine diphosphate (ADP) in the following order.

Protocol 1 (non-fatty-acid substrates):

(1) malate $2 \mathrm{mmol} / \mathrm{L}$ + pyruvate $10 \mathrm{mmol} / \mathrm{L}$ (complex Ilinked substrates), (2) glutamate $10 \mathrm{mmol} / \mathrm{L}$ (a complex I-linked substrate), (3) ADP (10 mmol/L), and (4) succinate $10 \mathrm{mmol} / \mathrm{L}$ (a complex II-linked substrate).

Protocol 1 (non-fatty-acid substrates):

(1) malate $2 \mathrm{mmol} / \mathrm{L}$, (2) octanoyl-l-carnitine 0.15 $\mathrm{mmol} / \mathrm{L}$, and (3) ADP $10 \mathrm{mmol} / \mathrm{L}$.

The respiratory rates (i.e., $\mathrm{O}_{2}$ consumption rates) were expressed as the $\mathrm{O}_{2}$ flux normalized to the mitochondrial protein concentration. Datlab software (Oroboros Instruments) was used for data acquisition and data analysis $[25,26,38]$.

Mitochondrial ROS generation simultaneously were measured with the mitochondrial respiratory capacity in the isolated mitochondria of LV using a spectrofluorometer (Fluorescence LED2-Module; Oroboros Instruments, Innsbruck, Austria) equipped with a respirometer, as previously described [39, 40]. Mitochondrial ROS were evaluated after the conversion of mitochondrial superoxide $\left(\mathrm{O}^{2-}\right)$ into $\mathrm{H}_{2} \mathrm{O}_{2}$ by the addition of superoxide dismutase (SOD). SOD (5 U/ $\mathrm{mL})$, horseradish peroxidase $(1 \mathrm{U} / \mathrm{mL})$, and Ample $^{\circ}$ 
UltraRed reagent $(10 \mu \mathrm{mol} / \mathrm{L}$; Thermo Fisher Scientific, Waltham, MA) were added to the chamber of the respirometer. $\mathrm{H}_{2} \mathrm{O}_{2}$ reacts with Amplex UltraRed in a 1:1 stoichiometry catalyzed by horseradish peroxidase, which yields the fluorescent compound resorufin. The excitation wavelength $(525 \mathrm{~nm})$ and fluorescence detection $(587 \mathrm{~nm})$ were selected. The fluorescence of resorufin was continuously monitored during the protocol 1 (along with the measurements of mitochondrial respiratory capacity). In order to eliminate the possible interference of substrates, the $\mathrm{H}_{2} \mathrm{O}_{2}$ generation rate was calibrated by the titration of $\mathrm{H}_{2} \mathrm{O}_{2}$ in $0.1 \mu \mathrm{mol} / \mathrm{L}$ increments before and after each substrate addition [39, 40].

\section{Measurement of mitochondrial iron contents}

After collecting isolated mitochondria using Mitochondrial Isolation Kit for Tissue (Pierce, MD, USA), mitochondrial iron contents were measured using a commercial Iron Assay Kit (BioAssay Systems, CA, USA) according to the manufacturer's protocol [41].

\section{Statistical analysis}

Statistical analyses were performed by commercially available software, GraphPad Prism, version 7.05
(GraphPad Software, CA, USA). Data are expressed as means \pm standard error (SE). Two-way analysis of variance (ANOVA) was used to analyze the effects of drug, time, and interaction. The Sidak test was performed for multiple-group comparisons of the means at each time point. One-way ANOVA was used to analyze the effects of the drug, followed by the Tukey test for multiplegroup comparisons of means. $P$-values of less than 0.05 were considered to indicate a statistically significant difference between 2 groups.

\section{Results}

Premedication with Pio prevents LV dysfunction caused by DOX treatment in the acute phase (day 7), but not in the hyperacute phase (day 1 )

To analyze the effects of LV function after the administration of DOX and Pio, we first analyzed 2 groups, i.e., standard diet + vehicle (Vehicle) and Pio + vehicle (Pio), on LV function as a preliminary study. There was no significant difference in \%FS, which is known as one of the simplest ways to assess LV function [23-25, 27, 42-44], between the 2 groups at 7 days after drug treatment (Vehicle: $55.3 \% \pm 2.4 \%$ vs. Pio: $53.5 \% \pm 1.8 \%, n=10$ each). Therefore, we performed the subsequent experiments on

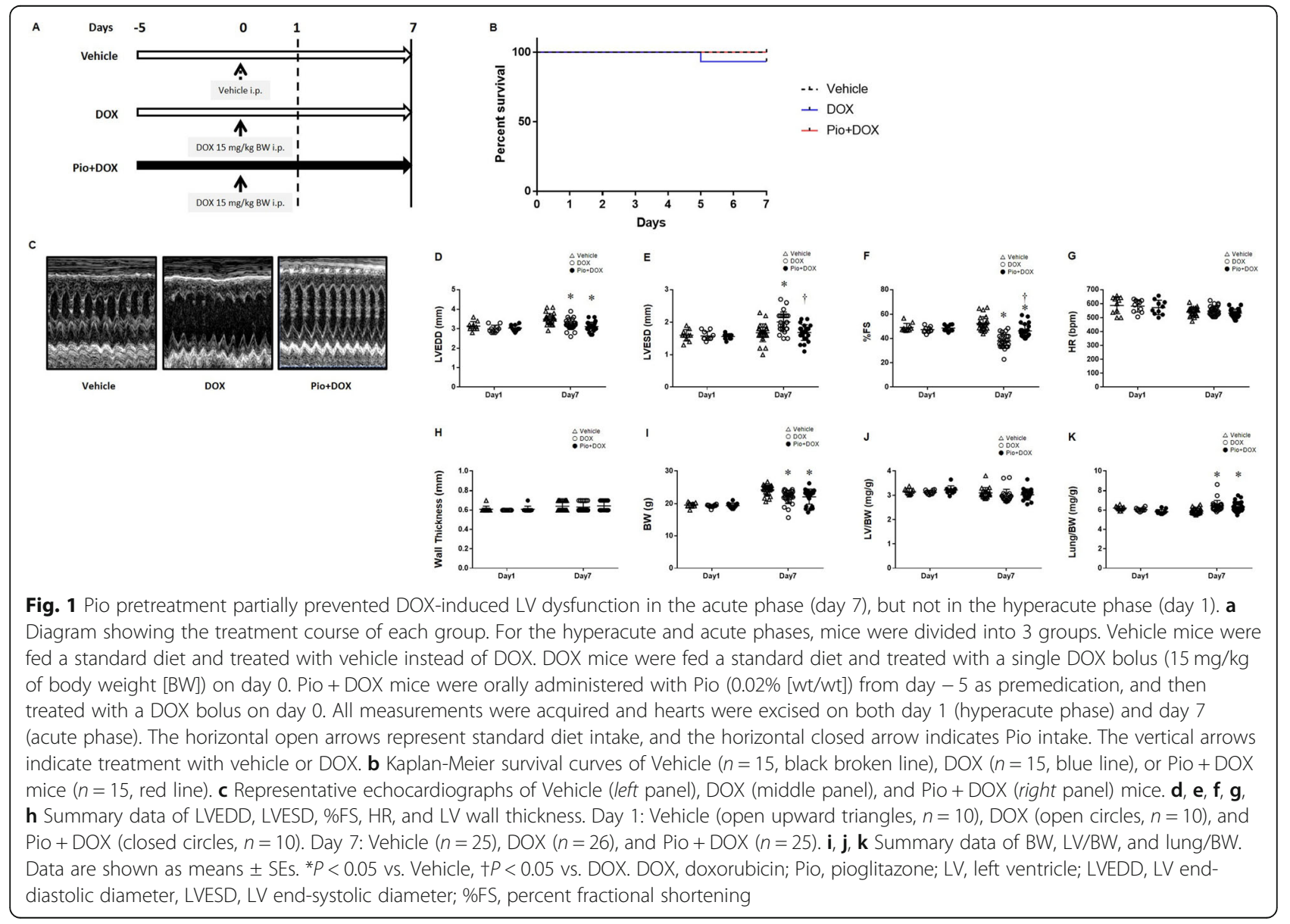


all mice except for the Pio group, i.e., the Vehicle, standard diet + DOX (DOX), and Pio + DOX groups.

In the protocol for the hyperacute and acute phases (Fig. 1a), only one mouse in the DOX group died, and no other mice died regardless of DOX or Pio treatment (Fig. 1b). LV function was evaluated by echocardiography at both 1 day and 7 days after DOX treatment via i.p. administration. In the hyperacute phase on day $1, \mathrm{LV}$ dysfunction was not yet detectable. However, in the acute phase on day 7 (Fig. 1c), DOX treatment caused LVEDD to be lower than that in vehicle-treated mice, regardless of a standard diet or Pio intake (Fig. 1d). Interestingly, LVESD in the DOX mice was higher than that in the Vehicle mice, even though LVESD in the Pio + DOX mice was comparable to that of Vehicle mice (Fig. 1e). \%FS in the DOX mice and Pio + DOX mice was decreased compared with that in Vehicle mice, and that in Pio + DOX mice was increased compared with that in DOX mice (Fig. 1f). Thus, DOX treatment induced an impairment in LV contractile function, whereas Pio treatment preserved LV contractile function to some extent, suggesting that premedication with Pio partially protected LV function in the acute phase of DOX-induced LV dysfunction. HR during the measurement of echocardiography did not differ among the 3 groups (Fig. 1g). Likewise, echocardiography displayed no differences in LV wall thickness among the 3 groups (Fig. 1h).

\section{DOX treatment decreased the body weight (BW) of mice} in the acute phase (day 7)

In the hyperacute phase on day 1 , no differences were observed among the groups in BW, LV/BW, and lung/ $\mathrm{BW}$. In the acute phase on day $7, \mathrm{BW}$ in DOX mice and Pio + DOX mice were lower than that in Vehicle mice, i.e., BW were lower in DOX-treatment mice than in vehicle-treated mice (Fig. 1i). The possible reason as to why BW in DOX-treated mice were decreased is the side effects of DOX itself, which include weight loss owing to the decrease in food intake after DOX administration. LV/BW did not differ among the groups (Fig. 1j). Lung/ BW in DOX mice and Pio + DOX mice was increased compared with that in Vehicle mice (Fig. 1k). This change did not appear to be caused by increased lung

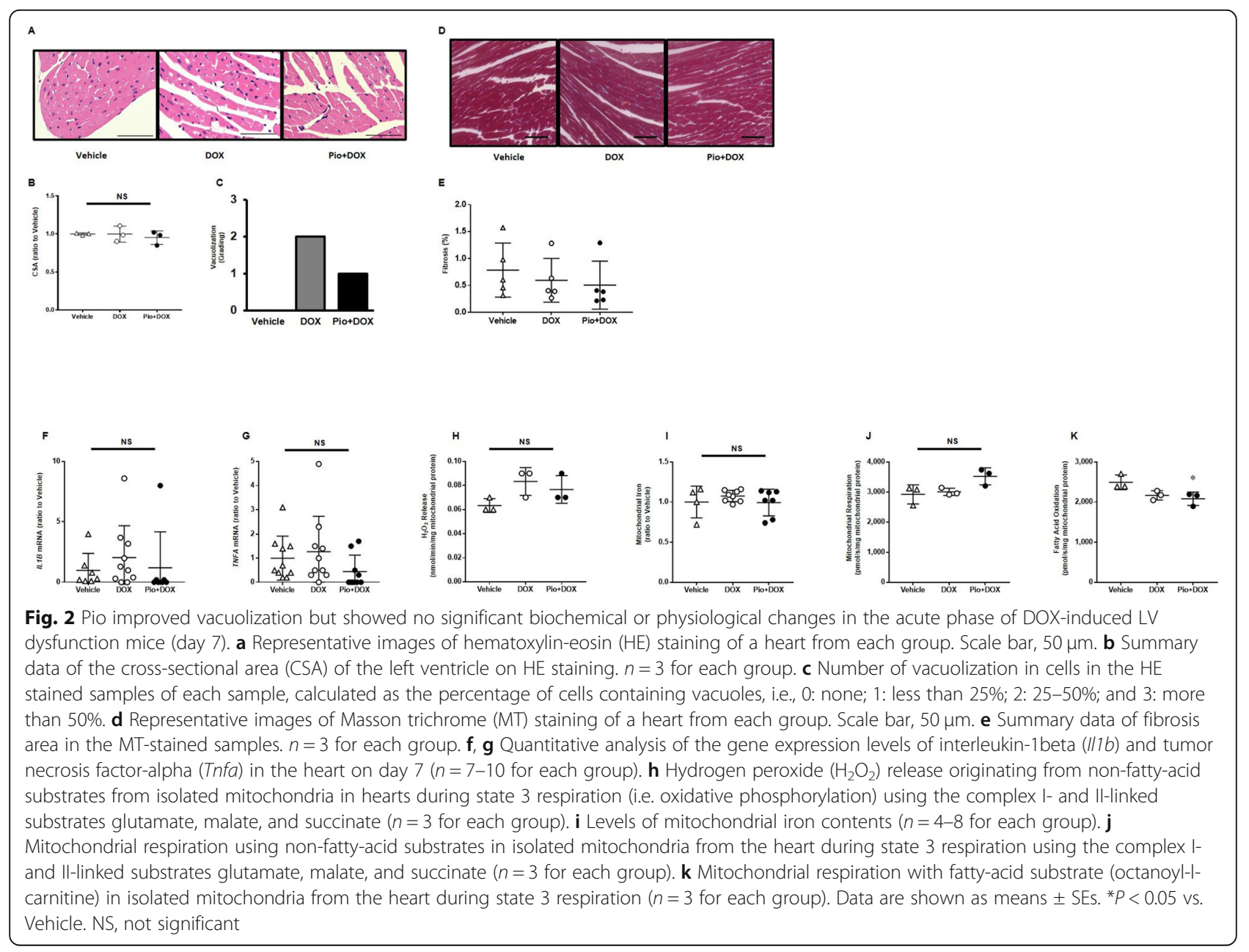


weight, which might imply a state of slight lung congestion caused by HF, but may rather be a result of decreased BW in these treatment groups.

\section{Pio inhibits vacuolization in cardiomyocytes treated with DOX}

Histological analysis with hematoxylin-eosin (HE) showed that myocyte cross-sectional areas did not differ among the 3 groups (Fig. 2a, b). These results suggested that myocyte cellular did not show hypertrophy or atrophy due to DOX and Pio treatment. The number of vacuolization in cells in DOX and Pio + DOX mice was higher than that in Vehicle mice, whereas that in Pio + DOX mice was lower than that in DOX mice (Fig. 2c). As assessed by Masson trichrome (MT) staining, the degree of myocardial fibrosis did not differ among the 3 groups (Fig. 2d, e).
No significant mechanistic changes occurred in the heart in the acute phase (day 7)

To clarify the underlying mechanism of DOX-induced acute LV dysfunction, we first measured the levels of proinflammatory cytokines. Gene expression levels of interleukin-1beta $(I l 1 b)$ and tumor necrosis factor-alpha (Tnfa) were not significantly increased in DOX-treated mice (Fig. 2f, g). Next, there was also no significant difference in mitochondrial reactive oxygen species (ROS), i.e., hydrogen peroxide $\left(\mathrm{H}_{2} \mathrm{O}_{2}\right)$ release rates from isolated mitochondria during mitochondrial respiration (Fig. 2h). In accordance with ROS production, the iron content in mitochondria did not differ among the groups (Fig. 2i). We measured mitochondrial state 3 respiration using glutamate, malate, and succinate as the complex Iand II-linked substrates, and found comparable results among the groups (Fig. 2j). We also measured

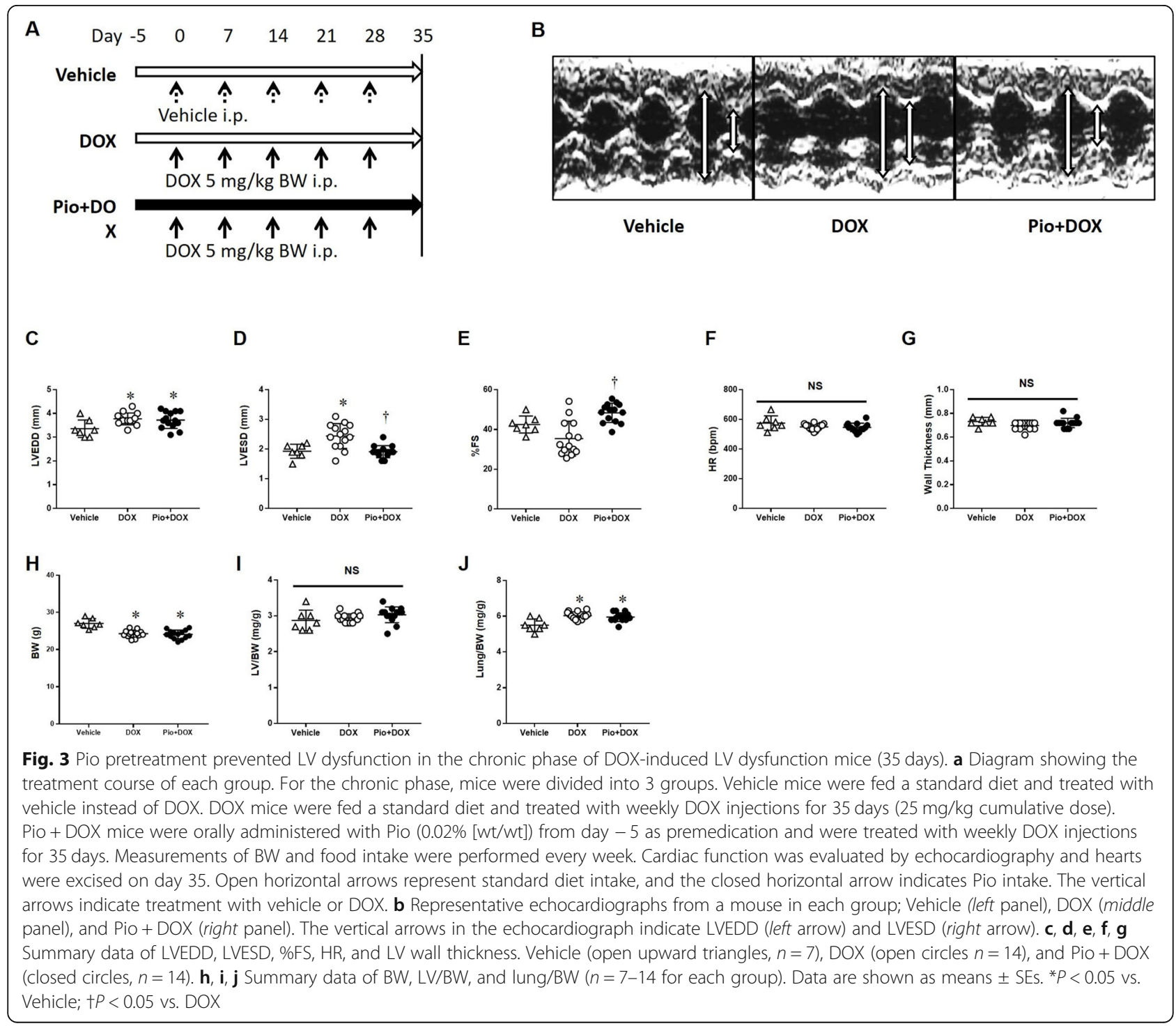


mitochondrial state 3 respiration using malate and octanoyl-l-carnitine, i.e., fatty acid oxidation (FAO). FAO in Pio + DOX mice was lower than that in Vehicle mice, whereas FAO in DOX and Pio + DOX did not differ between the groups (Fig. 2k).

\section{Premedication with Pio preserves LV function after DOX treatment in the chronic phase (day 35 )}

To confirm the effects of DOX and Pio in the chronic phase, we used a chronic model of DOX treatment, as shown in Fig. 3a. In this protocol for the chronic phase, DOX administration appeared to affect the amount of food intake (Table 1), even though no mice died in any group regardless of DOX or Pio treatment. LVEDD in both DOX and Pio + DOX mice was lower than that in Vehicle mice (Fig. 3b, c). LVESD in the DOX mice was higher than that in Vehicle mice, whereas LVESD in the Pio + DOX mice was comparable to that of Vehicle mice (Fig. 3d). \%FS in the DOX mice had a tendency to be lower than that of Vehicle mice, and that in Pio + DOX mice was substantially increased compared with that in DOX mice (Fig. 3e). Importantly, these patterns of LV function on day 35 were quite similar to those of day 7 . HR and LV wall thickness did not differ among the 3 groups (Fig. 3f, g). BW in DOX mice and Pio + DOX mice was decreased compared with that in Vehicle mice (Fig. 3h). LV/BW did not differ among the groups (Fig. $3 i$ ), even though lung/BW in DOX mice and Pio + DOX mice was increased compared with that in Vehicle mice (Fig. 3j).

Table 1 Body weights and food intake of chronic DOX-induced cardiomyopathy model mice during 35 days

\begin{tabular}{llll}
\hline $\boldsymbol{n}$ & \multicolumn{1}{l}{ Vehicle } & DOX & Pio + DOX \\
& $\mathbf{1 0}$ & $\mathbf{2 0}$ & $\mathbf{2 0}$ \\
\hline Body weights (g) & & & \\
Day 0 & $24.9 \pm 0.5$ & $26.3 \pm 0.3^{*}$ & $26.6 \pm 0.2^{*}$ \\
Day 7 & $25.5 \pm 0.5$ & $25.4 \pm 0.3$ & $25.7 \pm 0.2$ \\
Day 14 & $26.1 \pm 0.5$ & $25.4 \pm 0.3$ & $25.1 \pm 0.2$ \\
Day 21 & $26.7 \pm 0.5$ & $24.6 \pm 0.3^{*}$ & $24.2^{*} \pm 0.2^{*}$ \\
Day 28 & $27.1 \pm 0.5$ & $24.4 \pm 0.2^{*}$ & $23.9^{*} \pm 0.3^{*}$ \\
Day 35 & $27.4 \pm 0.5$ & $23.9 \pm 0.2^{*}$ & $23.4^{*} \pm 0.3^{*}$ \\
Food intake (g/day) & & \\
Day 0 & 2.6 & 3.1 & 3.4 \\
Day 7 & 2.7 & 2.1 & 2.1 \\
Day 14 & 2.8 & 2.5 & 2.4 \\
Day 21 & 2.7 & 2.2 & 2.1 \\
Day 28 & 2.6 & 2.2 & 2.0 \\
Day 35 & 2.5 & 2.0 & 1.9 \\
\hline Data are shown as the mean \pm SEs (body weights) or mean (food intake) ${ }^{*} P<$
\end{tabular}

Data are shown as the mean \pm SEs (body weights) or mean (food intake). ${ }^{*} P<$ 0.05 vs. Vehicle, $n$ Number, DOX Doxorubicin, Pio Pioglitazone

\section{Discussion}

This is the first report to demonstrate that premedication with Pio partially prevents LV dysfunction in both the acute and chronic phases, but not in the hyperacute phase, in mice treated with DOX, suggesting that the duration from DOX administration could be crucial for the emergence of the DOX-induced cardiomyopathy. Premedication with Pio may be a novel therapeutic strategy for the prevention of DOX-induced cardiomyopathy. However, molecular links between Pio and DOXinduced LV dysfunction remain largely elusive.

In terms of LV function, Pio treated mice without DOX treatment did not differ from vehicle mice on preliminary examination. This echocardiographic evaluation supports the idea that the effects of Pio on LV function are limited in the nondisease condition.

In addition to day 7, we also performed measurements on day 1 , because we assumed that differences in the effects of premedication and treatment after DOX administration would be found at an early stage. Similar to our results, there were no cardiomyopathy phenotypes (e.g., $\mathrm{LV}$ dysfunction and LV/BW) in the hyperacute phase until day 1 after DOX treatment [45-47]. Initially, chemotherapeutic agents do not appear to affect DOXinduced cardiomyopathy, which was also the case in our present study. Therefore, these results suggest that the duration from DOX administration, as well as the cumulative dose of DOX, could be crucial for the emergence of the DOX-induced cardiomyopathy. However, several signaling pathways, including cell death, were found to be altered during the hyperacute phase immediately after DOX treatment [45-47]. In fact, various studies demonstrated that drugs providing protective effects against DOX-induced acute cardiomyopathy were often administered before DOX treatment, and their effects might depend on the mechanism of the drug or the animal model [48-50]. Saraogi et al. observed that LV dysfunction was worse in rats treated with Pio $(10 \mathrm{mg} / \mathrm{kg} \mathrm{BW})$ for 14 days and with DOX injection $(15 \mathrm{mg} / \mathrm{kg} \mathrm{BW}$, single. dose) on the tenth day, than in rats treated with Pio only [51]. These results, which are the opposite of our results, were induced partially because the model used in their experiment was different from ours (animal, drug dose, and drug protocol). As there was no physiological evaluation in this previous study, judging from the side effects and oxidative stress data, we estimate that rat hearts were affected much more by DOX treatment than our mouse hearts. We believe that the extent of the DOX-induced heart damage occurring during the acute phase may determine whether Pio plays a protective or an aggravating role in DOX-induced LV dysfunction.

A previous report showed that an increase in LV endsystolic volume and a tendency of LV end-diastolic 
volume to decrease in DOX-treated mice were found in the acute phase after an administration of DOX $(20 \mathrm{mg} /$ $\mathrm{kg}$ BW single i.p.) [52]. Moreover, mouse models of DOX treatment vary, even in their i.p. administration; for example, a $10 \mathrm{mg} / \mathrm{kg}$ BW single bolus (acute proto$\mathrm{col})$, or 5 injections of $4 \mathrm{mg} / \mathrm{kg} \mathrm{BW} /$ week $(20 \mathrm{mg} / \mathrm{kg} \mathrm{cu}-$ mulative dose, chronic protocol) [53]. In the present study, for the acute model, we first used a $15 \mathrm{mg} / \mathrm{kg} \mathrm{BW}$ bolus injection via i.p. administration, because a simple protocol, i.e., a single injection, appeared to be preferable for determining the acute effects of DOX treatment. In addition, a much higher single-injection dose of $20 \mathrm{mg} /$ $\mathrm{kg} \mathrm{BW}$ or more readily caused mice to die in our preliminary experiments. Multiple lower-dose injections might be a more favorable choice, because a single-dose protocol makes it difficult to understand how DOX works in this situation. As cancer patients are usually treated with multiple low doses to limit adverse events, including cardiotoxicity, other protocols may also be useful, such as different doses and timings of injection. We next added mice receiving one injection of $5 \mathrm{mg} / \mathrm{kg}$ BW of DOX via i.p. administration per week for 5 weeks as the chronic model, and our results suggested that Pio may have protective effects on both acute and chronic DOX-induced LV dysfunction. From the point of view of clinical application, it is important to clarify whether the Pio concentrations achieved in mice can also be achieved in actual cancer patients. Moreover, such additional studies are expected to lead to the clarification of the mechanism of premedication with Pio, not only regarding pathology of the acute phase but also regarding pathology of the chronic phase.

Although Pio can alter metabolic status to some extent, it also has side effects. In fact, Pio has been used in various doses in rodents, from 0.005 to $0.1 \%$, but most often from 0.01 to $0.05 \%$ [15-17]. In addition, different doses might lead to different results. However, particularly in terms of reducing the side effects of Pio, such as fluid retention, which is a serious adverse reaction, $0.02 \%$ (wt/wt) of Pio appears to be a reasonable dose for rodents.

The models of DOX-induced cardiomyopathy or LV dysfunction with the heart in rodents have been well characterized with histopathology, serum markers, molecular pathways analysis. But we were unable to clarify the mechanism involved in our study, even though we analyzed inflammation, ROS production, and lipid metabolism. A previous paper proposed that PPAR $\gamma$ upregulation limits DOX-induced cellular toxicity [54]. This new perspective could give us supportive evidence with the phenomenon to the current study.

To date, no effective drug has been established against DOX-induced cardiomyopathy, even though several drugs, such as dexrazoxane, carvedilol, flavonoids, probucol, sildenafil, etc., are thought to be candidates [55]. Pio is well known to carry risks for symptomatic HF patients [11]. Accordingly, to date, no cardiologist has attempted the use of Pio for DOX-induced cardiomyopathy in clinical situations. However, with the recent increased interest in drug repositioning, defined as the process of finding new uses for existing drugs, we considered Pio as a candidate drug for the prevention of DOX-induced cardiomyopathy. Because premedication with Pio is used for patients with normal LV function, this usage does not compete with the idea that Pio is not recommended in patients with symptomatic HF. Unlike sudden-onset diseases, such as myocardial infarction and incipient heart failure, chemotherapy is a scheduled insult to the heart, and hence premedication with Pio may be reasonable from the perspective of the prevention of DOX-induced cardiomyopathy.

\section{Conclusions}

In conclusion, our findings may provide a new pathophysiological explanation for the therapeutic effects of Pio on DOX-induced cardiomyopathy; however, the molecular link between Pio and DOX-induced LV dysfunction remain largely elusive.

\section{Abbreviations}

ANOVA: Analysis of variance; BW: Body weight; DOX: Doxorubicin; HF: Heart failure; HR: Heart rates; i.p.: Intraperitoneal; LV: Left ventricle; LVEDD: LV enddiastolic diameter; LVESD: LV end-systolic diameter; \%FS: Percent fractional shortening; Pio: Pioglitazone; TZDs: Thiazolidinediones; SE: Standard error

\section{Acknowledgments}

The authors thank Yuki Kimura and Miwako Yamane for their technical assistance, and Ayae Oda, Misaki Kihara, Naoko Toshiro, Tsukusu Yamanaka, and Misato Kobayashi for their secretarial support, and H.A. Popiel for her critical reading of the manuscript.

\section{Authors' contributions}

T.F., S.T., and S.K. designed the study. T.F., S. M, S.T., N.K., H.N., R.S., and T.Y. performed the experiments and analyzed the data. T.F., S.T., and S.K. wrote the manuscript. All authors read and approved the final version of the manuscript.

\section{Funding}

This work was supported in part by Japanese Grants-In-Aid for Scientific Research (JP17K15979 [to T.F.], JP17H04758 [to S.T.], and 18H03187 [to S.K.]), a Grant-in-Aid for Challenging Exploratory Research (19 K22791 [to S.T.]), a grant from the Japanese Association of Cardiac Rehabilitation (to T.F.), a Hokkaido Heart Association Grant for Research (to T.F. and S.T.), grants from the Japan Foundation for Applied Enzymology (to S.T.), the Northern Advancement Center for Science \& Technology (to S.T.), a Japan Heart Foundation \& Astellas Grant for Research on Atherosclerosis Update (to S.T.), grants from the MSD Life Science Foundation (to S.T.), the Uehara Memorial Foundation (S.T.), the Cardiovascular Research Fund of Tokyo (to S.T.), the SENSHIN Medical Research Foundation (to S.T.), the Nakatomi Foundation (to S.T.), the Japan Heart Foundation (to S.T.), a Sasakawa Scientific Research Grant from The Japan Science Society (to S.T.), and a grant from the Center of Innovation Program from the Japan Science and Technology Agency (to S.T.).

\section{Availability of data and materials}

The datasets generated during or analyzed during the present study are available from the corresponding author upon reasonable request. 


\section{Declarations}

\section{Ethics approval and consent to participate}

The Hokkaido University Animal Research Committee approved all experimental procedures and methods of animal care (study approval no:: 13-0074). The Animal Care Guidelines for the Care and Use of Laboratory Animals of Hokkaido University Graduate School of Medicine and the Guide for the Care and Use of Laboratory Animals published by the US National Institutes of Health were applied to all experiments.

\section{Consent for publication}

Not applicable.

\section{Competing interests}

The authors declare that they have no conflicts of interest associated with this manuscript.

\section{Author details}

${ }^{1}$ Department of Cardiovascular Medicine, Faculty of Medicine and Graduate School of Medicine, Hokkaido University, Kita-15, Nishi-7, Kita-ku, Sapporo 060-8638, Japan. ${ }^{2}$ Faculty of Lifelong Sport, Department of Sports Education, Hokusho University, Ebetsu 069-8511, Japan. ${ }^{3}$ Research Fellow of the Japan Society for the Promotion of Science, Tokyo, Japan.

\section{Received: 10 January 2021 Accepted: 26 April 2021}

\section{Published online: 07 May 2021}

\section{References}

1. Cardinale D, Colombo A, Lamantia G, Colombo N, Civelli M, De Giacomi G, et al. Anthracycline-induced cardiomyopathy: clinical relevance and response to pharmacologic therapy. J Am Coll Cardiol. 2010;55(3):213-20.

2. Bristow MR, Thompson PD, Martin RP, Mason JW, Billingham ME, Harrison DC. Early anthracycline cardiotoxicity. Am J Med. 1978;65(5):823-32.

3. Minotti G, Menna P, Salvatorelli E, Cairo G, Gianni L. Anthracyclines: molecular advances and pharmacologic developments in antitumor activity and cardiotoxicity. Pharmacol Rev. 2004;56(2):185-229.

4. Zamorano JL, Lancellotti P, Rodriguez Munoz D, Aboyans V, Asteggiano R, Galderisi M, et al. 2016 ESC position paper on cancer treatments and cardiovascular toxicity developed under the auspices of the ESC Committee for practice guidelines: the task force for cancer treatments and cardiovascular toxicity of the European Society of Cardiology (ESC). Eur Heart J. 2016;37(36):2768-801.

5. Swain SM, Whaley FS, Ewer MS. Congestive heart failure in patients treated with doxorubicin: a retrospective analysis of three trials. Cancer. 2003;97(11): 2869-79.

6. Varga ZV, Ferdinandy P, Liaudet L, Pacher P. Drug-induced mitochondrial dysfunction and cardiotoxicity. Am J Physiol Heart Circ Physiol. 2015;309(9): H1453-67.

7. Rangwala SM, Lazar MA. Peroxisome proliferator-activated receptor gamma in diabetes and metabolism. Trends Pharmacol Sci. 2004;25(6):331-6.

8. Shiomi T, Tsutsui H, Hayashidani S, Suematsu N, Ikeuchi M, Wen J, et al. Pioglitazone, a peroxisome proliferator-activated receptor-gamma agonist, attenuates left ventricular remodeling and failure after experimental myocardial infarction. Circulation. 2002;106(24):3126-32.

9. Liao HW, Saver JL, Wu YL, Chen TH, Lee M, Ovbiagele B. Pioglitazone and cardiovascular outcomes in patients with insulin resistance, pre-diabetes and type 2 diabetes: a systematic review and meta-analysis. BMJ Open. 2017;7(1):e013927.

10. Ochodnicky P, Mesarosova L, Cernecka H, Klimas J, Krenek P, Goris M, et al. Pioglitazone, a PPARgamma agonist, provides comparable protection to angiotensin converting enzyme inhibitor ramipril against adriamycin nephropathy in rat. Eur J Pharmacol. 2014;730:51-60.

11. Lago RM, Singh PP, Nesto RW. Congestive heart failure and cardiovascular death in patients with prediabetes and type 2 diabetes given thiazolidinediones: a meta-analysis of randomised clinical trials. Lancet. 2007; 370(9593):1129-36

12. Shim JS, Liu JO. Recent advances in drug repositioning for the discovery of new anticancer drugs. Int J Biol Sci. 2014;10(7):654-63.

13. Bae YJ, Hwang YW, Yoon SY, Kim S, Lee T, Lee YS, et al. The effectiveness of automatic recommending system for premedication in reducing recurrent radiocontrast media hypersensitivity reactions. PLoS One. 2013;8(6):e66014.
14. Harada T, Ishimatsu Y, Hara A, Morita T, Nakashima S, Kakugawa T, et al. Premedication with clarithromycin is effective against secondary bacterial pneumonia during influenza virus infection in a pulmonary emphysema mouse model. J Pharmacol Exp Ther. 2016;358(3):457-63.

15. Kodama K, Toda K, Morinaga S, Yamada S, Butte AJ. Anti-CD44 antibody treatment lowers hyperglycemia and improves insulin resistance, adipose inflammation, and hepatic steatosis in diet-induced obese mice. Diabetes. 2015;64(3):867-75.

16. Cipolletta D, Feuerer M, Li A, Kamei N, Lee J, Shoelson SE, et al. PPARgamma is a major driver of the accumulation and phenotype of adipose tissue Treg cells. Nature. 2012:486(7404):549-53.

17. Li H, Sorenson AL, Poczobutt J, Amin J, Joyal T, Sullivan T, et al. Activation of PPARgamma in myeloid cells promotes lung cancer progression and metastasis. PLoS One. 2011;6(12):e28133.

18. Li L, Takemura G, Li Y, Miyata S, Esaki M, Okada H, et al. Preventive effect of erythropoietin on cardiac dysfunction in doxorubicin-induced cardiomyopathy. Circulation. 2006;113(4):535-43.

19. Zhu W, Zhang W, Shou W, Field LJ. P53 inhibition exacerbates late-stage anthracycline cardiotoxicity. Cardiovasc Res. 2014;103(1):81-9.

20. Zhu W, Soonpaa MH, Chen H, Shen W, Payne RM, Liechty EA, et al. Acute doxorubicin cardiotoxicity is associated with p53-induced inhibition of the mammalian target of rapamycin pathway. Circulation. 2009;119(1):99-106.

21. Lother A, Bergemann S, Kowalski J, Huck M, Gilsbach R, Bode C, et al. Inhibition of the cardiac myocyte mineralocorticoid receptor ameliorates doxorubicin-induced cardiotoxicity. Cardiovasc Res. 2018;114(2):282-90.

22. Hullin R, Metrich M, Sarre A, Basquin D, Maillard M, Regamey J, et al. Diverging effects of enalapril or eplerenone in primary prevention against doxorubicin-induced cardiotoxicity. Cardiovasc Res. 2018;114(2):272-81.

23. Furihata T, Kinugawa S, Takada S, Fukushima A, Takahashi M, Homma T, et al. The experimental model of transition from compensated cardiac hypertrophy to failure created by transverse aortic constriction in mice. Int J Cardiol Heart Vasc. 2016:11:24-8.

24. Kakutani N, Takada S, Nambu H, Matsumoto J, Furihata T, Yokota T, et al. Angiotensin-converting-enzyme inhibitor prevents skeletal muscle fibrosis in myocardial infarction mice. Skelet Muscle. 2020;10(1):11.

25. Maekawa S, Takada S, Nambu H, Furihata T, Kakutani N, Setoyama D, et al. Linoleic acid improves assembly of the CII subunit and CIII2/CIV complex of the mitochondrial oxidative phosphorylation system in heart failure. Cell Commun Signal. 2019;17(1):128.

26. Takada S, Masaki Y, Kinugawa S, Matsumoto J, Furihata T, Mizushima W, et al. Dipeptidyl peptidase-4 inhibitor improved exercise capacity and mitochondrial biogenesis in mice with heart failure via activation of glucagon-like peptide-1 receptor signalling. Cardiovasc Res. 2016;111(4): 338-47.

27. Nambu H, Takada S, Fukushima A, Matsumoto J, Kakutani N, Maekawa S, et al. Empagliflozin restores lowered exercise endurance capacity via the activation of skeletal muscle fatty acid oxidation in a murine model of heart failure. Eur J Pharmacol. 2020;866:172810.

28. Furihata T, Takada S, Kakutani N, Maekawa S, Tsuda M, Matsumoto J, et al. Cardiac-specific loss of mitoNEET expression is linked with age-related heart failure. Commun Biol. 2021;4(1):138

29. Kadoguchi T, Takada S, Yokota T, Furihata T, Matsumoto J, Tsuda M, et al. Deletion of $\mathrm{NAD}(\mathrm{P}) \mathrm{H}$ oxidase 2 prevents angiotensin I-induced skeletal muscle atrophy. Biomed Res Int. 2018;2018:3194917.

30. Helms SA, Azhar G, Zuo C, Theus SA, Bartke A, Wei JY. Smaller cardiac cell size and reduced extra-cellular collagen might be beneficial for hearts of Ames dwarf mice. Int J Biol Sci. 2010;6(5):475-90.

31. Chen $Y, Y u Q, X u C-B$. A convenient method for quantifying collagen fibers in atherosclerotic lesions by ImageJ software. Int J Clin Exp Med. 2017; 10(10):14904-10.

32. Sobirin MA, Kinugawa S, Takahashi M, Fukushima A, Homma T, Ono T, et al. Activation of natural killer T cells ameliorates postinfarct cardiac remodeling and failure in mice. Circ Res. 2012;111(8):1037-47.

33. Homma T, Kinugawa S, Takahashi M, Sobirin MA, Saito A, Fukushima A, et al Activation of invariant natural killer $T$ cells by alpha-galactosylceramide ameliorates myocardial ischemia/reperfusion injury in mice. J Mol Cell Cardiol. 2013;62:179-88.

34. Takada S, Kinugawa S, Hirabayashi K, Suga T, Yokota T, Takahashi M, et al. Angiotensin II receptor blocker improves the lowered exercise capacity and impaired mitochondrial function of the skeletal muscle in type 2 diabetic mice. J Appl Physiol (1985). 2013;114(7):844-57. 
35. Suga T, Kinugawa S, Takada S, Kadoguchi T, Fukushima A, Homma T, et al. Combination of exercise training and diet restriction normalizes limited exercise capacity and impaired skeletal muscle function in diet-induced diabetic mice. Endocrinology. 2014;155(1):68-80.

36. Tonkonogi M, Sahlin K. Rate of oxidative phosphorylation in isolated mitochondria from human skeletal muscle: effect of training status. Acta Physiol Scand. 1997;161(3):345-53.

37. Maekawa S, Takada S, Furihata T, Fukushima A, Yokota T, Kinugawa S. Mitochondrial respiration of complex II is not lower than that of complex I in mouse skeletal muscle. Biochem Biophys Rep. 2020;21:100717.

38. Mizushima W, Takahashi H, Watanabe M, Kinugawa S, Matsushima S, Takada S, et al. The novel heart-specific RING finger protein 207 is involved in energy metabolism in cardiomyocytes. J Mol Cell Cardiol. 2016;100:43-53.

39. Shirakawa R, Yokota T, Nakajima T, Takada S, Yamane M, Furihata T, et al. Mitochondrial reactive oxygen species generation in blood cells is associated with disease severity and exercise intolerance in heart failure patients. Sci Rep. 2019;9(1):14709.

40. Nakajima T, Yokota T, Shingu Y, Yamada A, Iba Y, Ujihira K, et al. Impaired mitochondrial oxidative phosphorylation capacity in epicardial adipose tissue is associated with decreased concentration of adiponectin and severity of coronary atherosclerosis. Sci Rep. 2019;9(1):3535.

41. Kusminski CM, Holland WL, Sun K, Park J, Spurgin SB, Lin Y, et al. MitoNEET-driven alterations in adipocyte mitochondrial activity reveal a crucial adaptive process that preserves insulin sensitivity in obesity. Nat Med. 2012;18(10):1539-49.

42. Matsumoto J, Takada S, Kinugawa S, Furihata T, Nambu H, Kakutani N, et al. Brain-derived neurotrophic factor improves limited exercise capacity in mice with heart failure. Circulation. 2018;138(18):2064-6.

43. Tsuda M, Fukushima A, Matsumoto J, Takada S, Kakutani N, Nambu H, et al. Protein acetylation in skeletal muscle mitochondria is involved in impaired fatty acid oxidation and exercise intolerance in heart failure. J Cachexia Sarcopenia Muscle. 2018;9(5):844-59.

44. Nambu H, Takada S, Maekawa S, Matsumoto J, Kakutani N, Furihata T, et al. Inhibition of xanthine oxidase in the acute phase of myocardial infarction prevents skeletal muscle abnormalities and exercise intolerance. Cardiovasc Res. 2020;117(3):805.

45. An L, Hu XW, Zhang S, Hu X, Song Z, Naz A, et al. UVRAG deficiency exacerbates doxorubicin-induced cardiotoxicity. Sci Rep. 2017;7:43251.

46. Shi J, Surma M, Wei L. Disruption of ROCK1 gene restores autophagic flux and mitigates doxorubicin-induced cardiotoxicity. Oncotarget. 2018;9(16):12995-3008.

47. Tscheschner $\mathrm{H}$, Meinhardt E, Schlegel P, Jungmann A, Lehmann LH, Muller OJ, et al. CaMKII activation participates in doxorubicin cardiotoxicity and is attenuated by moderate GRP78 overexpression. PLoS One. 2019;14(4):e0215992.

48. Montgomery MD, Chan T, Swigart PM, Myagmar BE, Dash R, Simpson PC. An alpha-1A adrenergic receptor agonist prevents acute doxorubicin cardiomyopathy in male mice. PLoS One. 2017;12(1):e0168409.

49. Kwatra M, Kumar V, Jangra A, Mishra M, Ahmed S, Ghosh P, et al. Ameliorative effect of naringin against doxorubicin-induced acute cardiac toxicity in rats. Pharm Biol. 2016;54(4):637-47.

50. Mantawy EM, El-Bakly WM, Esmat A, Badr AM, El-Demerdash E. Chrysin alleviates acute doxorubicin cardiotoxicity in rats via suppression of oxidative stress, inflammation and apoptosis. Eur J Pharmacol. 2014;728:107-18.

51. Saraogi P, Pillai KK, Singh BK, Dubey K. Rosiglitazone and pioglitazone aggravate doxorubicin-induced cardiomyopathy in Wistar rats. Biomed Aging Pathol. 2011;1(1):65-71.

52. Koleini N, Santiago JJ, Nickel BE, Sequiera GL, Wang J, Fandrich RR, et al. Elimination or neutralization of endogenous high-molecular-weight FGF2 mitigates doxorubicin-induced cardiotoxicity. Am J Physiol Heart Circ Physiol. 2019;316(2):H279-h288.

53. Marechal X, Montaigne D, Marciniak C, Marchetti P, Hassoun SM, Beauvillain $\mathrm{JC}$, et al. Doxorubicin-induced cardiac dysfunction is attenuated by ciclosporin treatment in mice through improvements in mitochondrial bioenergetics. Clin Sci (Lond). 2011;121(9):405-13.

54. Pakravan G, Foroughmand AM, Peymani M, Ghaedi K, Hashemi MS, Hajjari $M$, et al. Downregulation of miR-130a, antagonized doxorubicin-induced cardiotoxicity via increasing the PPARY expression in MESCs-derived cardiac cells. Cell Death Dis. 2018;9(7):758.

55. Mitry MA, Edwards JG. Doxorubicin induced heart failure: phenotype and molecular mechanisms. Int J Cardiol Heart Vasc. 2016;10:17-24.

\section{Publisher's Note}

Springer Nature remains neutral with regard to jurisdictional claims in published maps and institutional affiliations.

\section{Ready to submit your research? Choose BMC and benefit from:}

- fast, convenient online submission

- thorough peer review by experienced researchers in your field

- rapid publication on acceptance

- support for research data, including large and complex data types

- gold Open Access which fosters wider collaboration and increased citations

- maximum visibility for your research: over $100 \mathrm{M}$ website views per year

At BMC, research is always in progress.

Learn more biomedcentral.com/submissions 